\title{
Criticality Safety Considerations in
} the Geologic Disposal of Spent Nuclear Fuel Assemblies

\author{
B. F. Gore \\ G. W. McNair \\ S. W. Heaberlin
}

May 1980

Prepared for the

Office of Nuclear Waste Isolation

Pacific Northwest Laboratory

Operated for the U.S. Department of Energy

by Battelle Memorial Institute 


\title{
NOTICE
}

This report was prepared as an account of work sponsored by the United States Government. Neither the United States nor the Department of Energy, nor any of their employees, nor any of their contractors, subcontractors, or their employees, makes any warranty, express or implied, or assumes any legal liability or responsibility for the accuracy, rompleteness or usefulness of any information, apparatus, product or process disclosed, or represents that its use would not infringe privately owned rights.

The views. opinions and conclusions contained in this report are those of the contractor and do not necessarily represent those of the United States Government or the United States Department of Energy.

\author{
PACIFIC NORTHWEST LABORATORY \\ operated by \\ BATTELLE \\ for the \\ UNITED STATES DEPARTMENT OF ENERGY \\ Under Contract DE-AC06-76RLO 1830
}
Printed in the United States of America
Available from
National Technical Information Service
United States Department of Commerce
5285 Port Royal Road
Springfield, Virginia 22151

Price: Printed Copy $\mathbf{s}$ - Microfiche $\$ 3.00$

NTIS

-Pages Selling Price

$\begin{array}{ll}001-025 & \$ 4.00 \\ 026-050 & \$ 4.50 \\ 051-075 & \$ 5.25 \\ 076-100 & \$ 6.00 \\ 101-125 & \$ 6.50 \\ 126-150 & \$ 7.25 \\ 151-175 & \$ 8.00 \\ 176-200 & \$ 9.00 \\ 201-225 & \$ 9.25 \\ 226-250 & \$ 9.50 \\ 251-275 & \$ 10.75 \\ 276-300 & \$ 11.00\end{array}$




\section{8}

CRITICALITY SAFETY CONSIDERATIONS IN

THE GEOLOGIC DISPOSAL OF SPENT NUCLEAR

FUEL ASSEMBLIES

B. F. Gore

G. W. McNair

S. W. Heaberlin

May 1980

Prepared for

the Office of Nuclear Waste Isolation under its contract with the U.S. Department of Energy

Pacific Northwest Laboratory

Richland, Washington 99352 


\section{CONTENTS}

Page

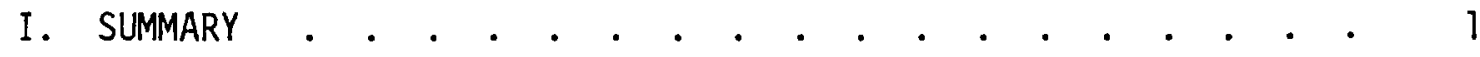

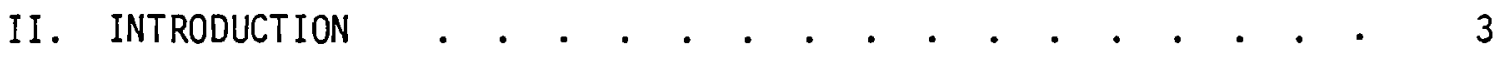

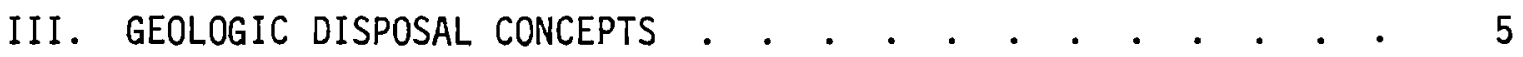

IV. TIME FRAMES OF IMPORTANCE.$\quad \cdot \quad \cdot \quad \cdot \quad \cdot \quad \cdot \quad \cdot \quad \cdot \quad \cdot \quad \cdot \quad \cdot \quad \cdot \quad 9$

Initial . . . . . . . . . . . . . . . . . . 9

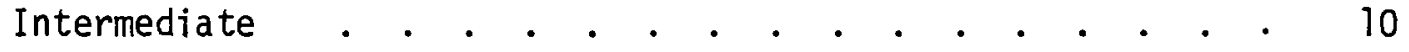

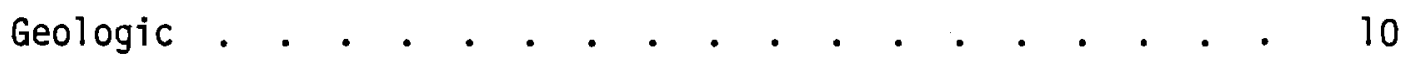

V. CRITICALITY SAFETY CONCERNS . • • • • • • . . • . • . 12

Mass: Fresh Fuel . . . . . . . . . . . . . . 15

Geometry: Fresh Fuel . . . . . . . . . . . . . 15

Isotopic Composition and Licensing . . . • . . . . . 17

Experimental Verification of Burnup . . • . . . . . . 21

Moderation . . . . . . • . • . • • • . . . . 24

VI. EFFECTS OF MODERATOR EXCLUSION BY CLOSE-PACKED FUEL RODS . 27

VII.' RESEARCH TOPICS FOR FUTURE STUDY . • • • • • • • • . • . . 42

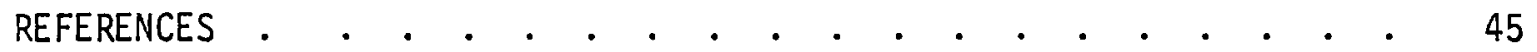




\section{LIST OF FIGURES}

Page

1. Canistered Spent Fuel Emplaced in Sleeved Holes . . . . . 7

2. Calculated Radii of Critical Lattices . . . . . . . . 31

3. Calculated Values of Neutron Multiplication for Critical Experimental Lattices . . . . . . . . . 33

4. Critical Lattice Radii With Water and Concrete Reflectors . . . . . . . . . . . . . . . . 35

5. Effects of Uniform Fuel Rod Disintegration . . . . . 36

6. Effects of Cladding Separation During Fuel Disintegration . . . . . . . . . . . . . . . 37

7. Effects of Limits to Close-Packing Caused by Fuel Rod Bowing . . . . . . . . . . . . . . 39

\section{LIST OF TABLES}

I. Factors Influencing Criticality . . . . . . . . . 13

II. PWR Fuel Rod Data . . . . . . . . . . . . . . 29

III. Benchmark Experiment Fuel and Cladding Data . . . . . . 32 


\section{SUMMARY}

This study identifies and addresses problems encountered in assessing the criticality potential of spent fuel disposal in deep geologic repositories. Topics are identified for future study which will provide information and, hopefully, resolution to the problems discussed.

Features of geologic disposal which hamper the demonstration that criticality cannot occur therein include possible: changes of shape and form; intrusion of water as a neutron moderator; and selective leaching of spent fuel constituents. The effects of these changes on the criticality potential of spent fuel are discussed.

Spent fuel disposal concepts call for packaging fuel assemblies individually in canisters for emplacement in a geologic repository. Inclusion of a stabilizer material within the canister is considered in some concepts. However, a single unirradiated PWR fuel assembly contains several times as much fresh fuel as is required for criticality in spherical geometry with optimum water moderation. Fissile depletion due to burnup reduces the neutronic reactivity of spent fuel below that of fresh fuel. However, no commercial spent fuel storage facility has ever been licensed under the assumption that the neutronic reactivity of the fuel was reduced below that of fresh fuel. It is to be expected that a significant amount of researcil, experimentation and demonstration will be required to set a new precedent for regulatory action.

If the criticality safety of spent fuel disposal depends significantly upon burnup of fissile fuel material having taken place, then independent measurements verifying the occurrence of burnup should be performed prior to disposal of the fuel. The status of nondestructive analysis methods which might provide such verification is discussed, along with special requirements which the assay of whole assemblies of radioactive spent fuel places upon measurement systems. It is concluded that, while such systems have not yet 
been demonstrated, design studies indicate that they should be feasible using existing technology.

Calculations were performed to assess the potential for increasing the allowed size of a spent fuel disposal canister if potential water intrusion were limited by close-packing the enclosed rods. Such a scheme would be of limited applicability, but might be appropriate if geometry were maintained as when canisters were placed in holes bored into solid rock. These calculations took no credit for fissile burnup, and assumed unirradiated fuel . Study of this concept resulted in identification of several factors which severely limited the potential of this application. The theoretical limit of hexagonal close-packing cannot be achieved due to fuel rod bowing during high temperature irradiation in the reactor core. Clamping or compression is not recommended since it could fracture the cladding releasing fission products. If fuel rod disintegration occurs, water in side and end clearance gaps would increase moderation. If during disintegration cladding separates from the resulting fuel-water mixture, uranium density would be increased, increasing neutronic reactivity. It is concluded that disposal canisters should be sized on the basis of assumed optimum moderation of their contents for the sake of conservatism and straightforward analysis practice. This would not preclude close-packing rods inside canisters, which would increase the packing efficiency at the expense of increased handling required for fuel bundle disassembly and rod packing.

Several topics for additional research were identified during this limited study. Most important is determination of acceptibility criteria concerning fuel quantities and residual fissile content in canisters of spent fuel destined for geologic disposal. Other topics include determination of minimum quantities and compositions of U-Pu mixtures which could be critical in soil under conditions of dryness; identification and assessment of geologic scenarios which could result in criticality in a repository to determine if they are credible; and evaluation of the magnitude, duration and consequences of critical excursions resulting from any credible scenarios which may be identified. It is planned to address at least the first two of these topics during the coming fiscal year. 


\section{INTRODUCTION}

Due to the executive decision not to reprocess spent nuclear fuel assemblies from commercial light water reactors (LWR's), studies are being carried out to determine how to dispose of this material. Of the many alternatives which have been proposed, the concept of deep geologic disposal has received most study to date. It has received primary consideration in major DOE studies ${ }^{1,2}$ of spent fuel disposal. This present study is confined to effects encountered in geologic repositories. It addresses the problems encountered in assessing the criticality potential of spent fuel emplaced therein.

Section Three of this report describes the present concept of spent fuel disposal in geologic repositories. This information is condensed from information published in other DOE documents. 1,2 Then in Section Four the temporal sequencing of effects which may occur in geologic repositories is discussed and compared with the lifetimes of the fissile species involved, to identify time frames relevant to criticality safety concerns. In Section Five the features of geologic disposal which make it difficult to demonstrate that criticality cannot occur under any conceivable sequence of geological conditions are described. Concerns identified include the amount of fissile material actually remaining in a spent fuel assembly, changes in geometry resulting from geological processes, and the availability of water as a neutron moderator. The conservatism routinely employed in criticality safety analyses and required by licensing agencies is also discussed in this section, along with the status of experimental measurement systems which might be used to independently demonstrate that spent fuel sent to geologic disposal has an acceptably low fissile content.

In Section Six the results of a limited study on the effects of moderator exclusion by close-packing fuel rods in a disposal canister are presented. In this study no credit was taken for reduction by burnup of the fissile content of the fuel since there is no precedent for 
including burnup effects in the licensing review of any commercial spent fuel storage facility. Calculational results indicating the potential for increasing the allowed size of disposal canisters are presented. These are followed by discussion of a series of complicating factors related to potential disintegration of the fuel rods within the canister. Limitations on close-packing, including the effects of fuel rod bowing, and clearance required for fuel insertion into the disposal canister, are shown to severely limit allowable increases in canister size.

The final Section Seven presents topics which have been identified during this year's work as needing further study to allow an adequate demonstration of criticality safety in the disposal of spent fuel. It is intended that ongoing studies in this program will address these topics. 


\section{GEOLOGIC DISPOSAL CONCEPTS}

The objective for the geologic disposal of spent fuel is to prevent this radioactive material from becoming a threat to human health during its hazardous lifetime. 1 The disposal of spent fuel in deep geologic repositories is considered an effective means of permanent isolation of this material which is within the scope of available technology. ${ }^{2}$ The Office of Nuclear Waste Isolation (ONWI) operated by Battelle Memorial Institute for DOE is presently conducting broadly-based studies on the characteristics of repository media, repository design and site selection criteria. In addition to this work on criticality, studies are being performed in many other fields. Concepts presented in this section represent present thinking. They are not all-inclusive.

ONWI is currently engaged in investigation of sites for a repository in a salt formation with plans for investigation of other geologic media. Ongoing studies in the Columbia River Flood Basalt are being conducted by Rockwell Hanford Operations while similar studies of the Nevada Test Site shales and granites are being conducted by the DOE Nevada Operations Office.

It is anticipated ${ }^{1}$ that spent fuel will be packaged in some form of a canister prior to geologic disposal. Each canister would contain an as-yetundetermined number of spent fuel rods. It is frequently assumed that the rods would be packed as intact fuel assemblies as removed from a reactor core. The canister would provide containment for contamination which is in and on fuel rods during handling and emplacement into a repository, and also during an initial period of "easy retrievability" prior to repository backfilling and sealing. Following repository closure, containment by the canister would continued for an undefined time which is dependent upon canister design. This could last for hundreds of years, and possibly up to thousands of years. 3

The role of the canister under disposal conditions is not well defined. ${ }^{3}$ In its simplest form the canister might consist of nothing more than a section 
of mild steel pipe closed at both ends. Such a canister might be filled with an inert gas such as helium to minimize oxidation of the fuel cladding and to facilitate leak checking. Or, an advanced package might be utilized which was designed to retain its integrity for up to 1000 years. ${ }^{3}$ such a package could be made from thick corrosion resistant metals, polymers (including epoxies), ceramics, glasses, or cements. In addition, the canister might be lined with one of these materials, and it might also be filled with a stabilizer material. Stabilizers could enhance corrosion resistance of the package, control the geometry of the spent fuel when its cladding fails, exclude water or minimize the amount which could infiltrate through eventual leaks, and perhaps impede the eventual escape of leached radionuclides by their sorption characteristics.

Repositories for the geologic disposal of packaged spent fuel may be located in salt, granite, shale and/or basalt formations. 'They may be constructed by conventional room-and-pillar mining techniques several thousand feet below the surface. Canistered spent fuel may be emplaced vertically in holes or trenches, drilled or excavated into the floor of the emplacement rooms. ${ }^{2}$ Alternatively, it may be emplaced horizontally.

During the period of repository expansion it is likely that the repository would be operated in a readily retrievable mode. This would ensure examination of the entire host rock formation prior to backfilling of emplacement rooms. To prevent canister damage or corrosion, emplacement might be into sleeved holes as shown in Figure 1 taken from Reference 2. In addition to maintaining an open hole for easy canister insertion and removal, the hole sleeve might be designed to function as a barrier between the radjoactive contents of the spent fuel and the environment. This could result in massive shells of special cements cast in place, polymer barriers located some distance away from the canister for protection against heat or radiation, or other impervious vessels specially bedded in the surrounding rock. However, the method of repository operation during retrievability, and the duration and ease of retrievability are not yet defined. 


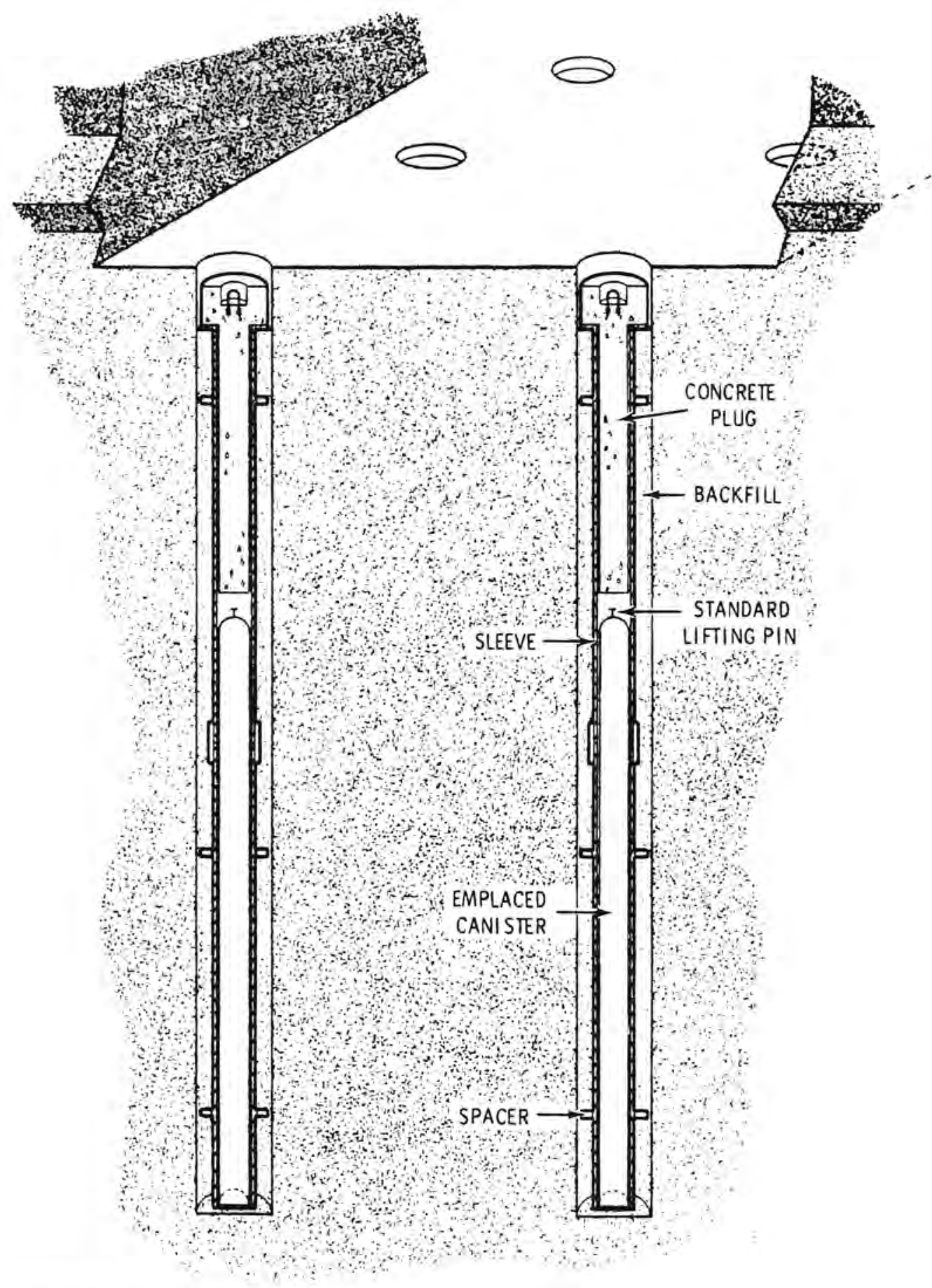

FIGURE 1. Canistered Spent Fuel Emplaced in Sleeved Holes 
When it was determined that the entire repository was suitable for spent fuel disposal, canister emplacement rooms would be backfilled after their emplacement holes were filled. After a repository was filled, at some not yet defined time, entrance shafts would be sealed and backfilled, and surface structures removed. Spent fuel disposal would then be permanent. 


\section{TIME FRAMES OF IMPORTANCE}

Criticality is of concern with spent fuel because it contains considerable quantities of ${ }^{235} \mathrm{U}$ and ${ }^{239} \mathrm{Pu}$. These fissile isotopes have half lives of $7 \times 10^{8}$ and $2.4 \times 10^{4}$ years, respectively. Consequently, the potential for criticality with this material continues for long times. This potential clearly outlasts the ability of manmade structures to control the physical conditions to which it is exposed.

Three time frames may be identified in which different degrees of control exist over the physical condition of spent fuel in geologic disposal. Since control of the physical conditions of fissile material is a fundamental principle of criticality prevention, these time frames are described below and their significance is discussed.

$\underline{\text { Initial }}$

A period of retrievability exists between emplacement of canistered spent fuel in a repository and the backfilling and sealing of the repository. The duration of this period would be a few years to several decades. During this period, the canister containing the spent fuel is expected to remain leak tight so that canister retrieval would not be complicated by the escape of radioactive materials. Consequently, conditions with in the canister should remain essentially the same as when fuel was loaded into the canister. From the standpoint of criticality prevention, the exclusion of water from the region containing fissile material is the most important characteristic of this period. Others include the maintenance of canister geometry, the presence of any stabilizer material loaded into the canister with the fuel, the maintenance of fuel rod and pellet geometry, and the presence of any neutron poison materials either loaded with the stabilizer or pre-existing in the fuel rods (fission products, for instance). In addition, during this period the separation of neighboring canisters by known thicknesses of rock or salt is ensured. Consequently, the potential for criticality to occur during this period would not be expected to change 
from that existing at emplacement. Assessment of this potential, however, must include the possibility of off-normal conditions. One potentially credible event would be repository flooding caused either by surface flooding, or by the unforeseen excavation during repository expansion into a source of groundwater.

\section{Intermediate}

The period of retrievability ends with the backfilling of the emplacement room. It is followed by an intermediate period during which the physical condition of the canister and its contents is slowly degraded. The duration of this period could be many years to many centuries. Breaching of the canister by corrosion or distortion of the surrounding medium would allow the entry of groundwater into the fuel region if it were present in the backfilled repository. The possibility of water moderation within the canister is the most important characteristic of this intermediate period from the criticality prevention standpoint, though criticality could not occur without other changes as well. Other possible changes include distortion of the canister, erosion or leaching of stabilizer material from the fuel rod region, failure of fuel rod cladding, and disintegration of fuel pellets. Distortion of the surrounding geological medium may also occur during this period.

\section{Geologic}

The transition from the intermediate period to a final geologic period is characterized by disintegration of the canister and fuel. This period, starting several hundred to several thousand years after fuel emplacment in the repository, includes the thousands of years required for the fissile isotopes to decay away. It is clearly the longest of the three periods. During this period, all control is lost over the physical conditions to which the canister contents are exposed. Not only are canister geometry and fuel form lost, but stabilizer material is subject to washout, as is neutron poison material which might have been inserted into the canister. Fission products which act as neutron poisons may be leached away leaving 
the less soluble fissile actinides behind. Or, fissile isotopes could be leached and selectively re-accumulated without the fission products. Geologic distortion of the surrounding medium could alter the separation between canister locations, or thermally driven migration could yield this effect in salt deposits. During this period, the primary determinant of changes which could occur would be the geologic stability of the host medium for the repository. For instance, cylindrical geometry might be maintained by boreholes drilled in stable rock despite canister disintegration. Water infiltration might be precluded by unfractured monolithic rock structures into which the repository might be excavated. Nevertheless, the uncertainty in geologic conditions during this period must be included in a conservative way in analyses of the criticality safety of this disposal concept. 


\section{CRITICALITY SAFETY CONCERNS}

It is the objective of this project to identify all situations in which a nuclear chain reaction (criticality) could occur and to define 1 imitations to be placed on handling and disposal conditions so that the possibility of accidental criticality is minimized. The neutronic reactivity of fissile systems is influenced by many factors. Some of the most important ones are identifed in Table I. These factors interact in a complex fashion.

In spite of the complexity indicated by Table I, there exist certain simple limits which bound conditions for which criticality cannot occur. The minimum critical mass (MCM) is one such limit. For fissile material of a given isotopic composition the MCM is the smallest mass of that material which can be made critical for any possible conditions of moderation, geometry and reflection. Geometrical limits also exist, defining the radii of the smallest spheres and cylinders and the height of the thinnest slabs in which criticality is possible for a given material.

Whenever possible, demonstration of the criticality safety of a system is accomplished by assuring that some minimum critical parameter value (such as the MCM) cannot be exceeded. Unfortunately, however, minimum critical values are usually inconveniently small. For instance, the MCM for ${ }^{235} \mathrm{~J}$ and ${ }^{239} \mathrm{Pu}$ solutions are $820 \mathrm{~g} \mathrm{U}$ and $513 \mathrm{~g}$ Pu respectively. ${ }^{4}$ Corresponding minimum safe cylinder diameters are just 7.1 and $4.3 \mathrm{~cm}$, respectively. ${ }^{4}$ As another example, the minimum critical cylinder diameter for $\mathrm{UO}_{2}$ rods having an isotopic composition of $5 \mathrm{wt} \%{ }^{235} \mathrm{U}$ and $95 \mathrm{wt} \%$ $238 \mathrm{U}$ in 1 ight water with a large light water reflector, regardless of the height of that cylinder is about $24 \mathrm{~cm}$. Any cylinder of $\mathrm{UO}_{2}$ rods of that composition in water which has a diameter less than $24 \mathrm{~cm}$ is critically safe. Any such arrangement of $\mathrm{UO}_{2}$ rods in a $25 \mathrm{~cm}$ diameter cylinder may be safe; however, we know that there is some arrangement which is not. 


\section{TABLE I. Factors Influencing Criticality}

Fissile Materials

- Mass

- Isotopic composition

- Density

Neutron Moderators

- Materials present

- Amount

- Density

Fissile-Moderator Region

- Size

- Shape

Neutron Reflectors Outside Fissile-Moderator Region

- Materials

- Density

- Moderating properties

Neutron Absorbers (Poisons)

- Material

- Amount

- Location

Interacting Regions of Fissile Material

- Number

- Separation

- Interposed non-fissile materials

- Planar vs. 3-dimensional arrays 
The demonstration that a system is safe from the possibility of accidental criticality may still be possible when fissile mass exceeds the minimum critical mass and when container sizes exceed minimum safe values; however, it becomes more complicated. Process restrictions on moderation (dry systems) or concentration (dilute systems) can be included in the analysis, allowing a demonstration that criticality cannot occur within the range of allowed conditions. From the standpoint of safety it is preferable that such restrictions be imposed by the physics or chemistry of a given process. Less certain are restrictions imposed upon the actions of system operators, since mistakes are possible.

The demonstration of safety requires that off-normal situations cannot result in unacceptable results--in our case, criticality. Consequently, Criticality Safety Analysis (CSA) specialists view operations differently than process engineers. Analyses are based upon the worst possible combination of the worst allowed circumstances--a point of view which can be quite vexing to process engineers. However, little insight is gained by studying cases less demanding than the worst case.

The conservatism of CSA work described in the preceding paragraph is carried even further in the "Two Contingency Principle" which requires that criticality be precluded even if any single restriction should be lost (a contingency). Present industrial practice is to require that system design meet the two contingency principle, although exceptions may be made where shielding and containment protect workers from the effects of an accidental criticality. Demonstration that a system meets the two contingency principle requires that a series of analyses be performed which show that when each restriction is lost (singly) and simultaneously all other conditions are the worst allowed, the system remains subcritical. 


\section{Mass: Fresh Fue 1}

A $17 \times 17$ rod PWR fuel assembly contains 264 fuel rods which have a total $\mathrm{UO}_{2}$ content of about $520 \mathrm{~kg}$. The initial enrichment of ${ }^{235} \mathrm{U}$ in the fuel may vary with the position in the reactor core into which the assembly is to be located. Enrichments exceeding $3 \%$ are common. Consequently, we have chosen $3.5 \%$ enrichment as characteristic of unirradiated fresh fuel.

A single assembly of fresh fuel contains sufficient fissile material to be of criticality concern. For instance, a water reflected sphere containing only about $80 \mathrm{~kg}$ of homogeneous $\mathrm{UO}_{2}$ - water mixture having $3.5 \%$ enrichment could yield criticality. ${ }^{4}$ The fuel assembly thus contains roughly 6.5 times as much fuel mass as that required for criticality in the most favorable geometry.

\section{Geometry: Fresh Fuel}

Despite the large amount of $\mathrm{UO}_{2}$ contained in an assembly of fresh fuel, the assembly is subcritical when immersed in water because of its shape-- roughly 8.5 inches $(21.6 \mathrm{~cm})$ square by $12.5 \mathrm{ft}(3.8 \mathrm{~m})$ long. Due to the long, thin shape, neutrons escape from the fuel assembly more readily than from a sphere, and a self-sustaining chain reaction cannot occur. However, although a single fresh fuel assembly in water would be subcritical, its neutronic reactivity is definitely non-trivial. An effective neutron multiplication slightly greater than 0.9 would result $t^{5}$, where 1.0 indicates the critical condition.

The diagonal width of such a fuel assembly is roughly 12 inches $(30.5 \mathrm{~cm})$. A reasonable inside diameter for a cylindrical canister to contain it would be 13 inches $(33.0 \mathrm{~cm})$. However, a 13 inch $(33.0 \mathrm{~cm})$ diameter cylinder of optimally moderated $\mathrm{UO}_{2}$-water mixture fully reflected by water would be critical. A hypothetical scenario leading to accidental criticality in spent fuel disposal may therefore be postulated. The scenario requires inadvertent disposal of an assembly of fresh fuel, or perhaps disposal of 
an assembly where failed cladding or other mechanical failure rendered the fuel useless prior to significant in-reactor exposure. It also requires that the fuel disintegrates eventualiy, and that water intrudes into the repository region.

Since all of these things cannot be proven to be impossible, the simple, sweeping, conservative demonstration of criticality safety in the disposal of complete assemblies of PWR fuel is not possible here. This does not mean that spent fuel disposal cannot be designed and demonstrated to be adequately safe from accidental criticality, but only that such design and demonstration requires more sophistication. For instance, the diameter of disposal canisters might be restricted to be smaller than the critical diameter of a cylinder of optimally moderated $\mathrm{UO}_{2}$-water mixture. This, however, would probably require the separation of complete fuel assemblies into smaller pieces. The additional handling required by such a restriction would be undesirable from the standpoint of cost and increased radiation exposure of workers.

Another alternative would be to include stabilizer materials within each disposal canister, occupying the spaces between fuel rods within fuel assemblies. These materials would maintain the geometry of the fuel, should fuel rod disintegration occur. They would also occupy space which could otherwise fill with water, limiting moderation. Other functions which stabilizers could perform include the improvement of corrosion resistance (solid metal, glass or ceramic materials), or the reduction of radionuclide transport after canister failure (particulate ion-exchange materials).

Neutron poison materials could also be incorporated into stabilizer materials to reduce the neutronic reactivity of canister contents. However, if stabilizer materials function to prevent criticality it must be demonstrated that they will remain in place during the geologic time spans required for the fissile nuclides to decay. The possibility of using spent fuel rods, close-packed, as self-stabilizer material is discussed in Section VI of this document. 
Yet another alternative would be to include the effects of in-reactor exposure in demonstrations of criticality safety. This alternative is discussed in the following subsection.

\section{Isotopic Composition and Licensing}

The nuclear reactivity of spent fuel depends on a number of factors. One of these is the ${ }^{235} \mathrm{U}$ content remaining in the fuel. This in turn depends upon both the initial enrichment of the fuel and the amount consumed in the reactor, termed burnup. The amount of fissile burnup depends upon the energy which has been extracted, and how much fuel it was extracted from. It is commonly expressed in units of megawatt days of energy per metric ton of fuel, or MWD/MT. Present fuel designs are based upon an assumed useful fuel lifetime of roughly 30,000 MW/MT. Variations are found with different vendors and specific situations.

The reader may well question why this discussion of criticality concerns with spent fuel disposal has so far been illustrated with examples using fresh fuel. The answer lies in the conservatism inherent in criticality safety analyses--every factor which cannot be controlled is assumed to take its most unfavorable configuration. As was discussed in the introduction, many factors influence the residual fissile content of spent fuel. In the absence of stringent controls to determine, verify and assure the effects of fissile burnup, it is not adequate to base a demonstration of criticality safety upon assumptions of extensive burnup.

The avoidance of accidental criticality is considered very important by regulatory bodies such as the Nuclear Regulatory Commission which licenses commercial facilities and by the DOE which regulates the research facilities which it sponsors. The conservatism which these agencies require before agreeing that criticality safety has been adequately demonstrated is illustrated by the fact that there has never been a single commercial spent fuel storage basin licensed under the assumption that the nuclear reactivity of the spent fuel was reduced from that of fresh fuel. 
The decision to defer the reprocessing of spent fuel has caused the accumulation of this material in storage basins at reactor sites nationwide. This was recognized as a problem as far back as 1974, and since that time 60 of the country's 67 operating light water reactors have initiated activities to expand their spent fuel storage capability. An instructive review of this situation was presented by an NRC staff member at the 1979 annual meeting of the ANS in Atlanta, Georgia. ${ }^{8}$ As a result of the need, storage basin designs have evolved considerably, allowing increased amounts of fuel to be stored in a given size basin. Storage racks have been compacted, fixed neutron poison materials have been incorporated, and double-tiered racks have been designed.

The evolution of water basin spent fuel storage designs is of importance to the discussion of spent fuel disposal because both require an evolution of regulatory licensing philosophy. The requirements of the NRC 1 icensing review have not changed. These requirements state, in part, that,

"Criticality information (including the associate assumptions and input parameters) in the SAR must show that the center-tocenter spacing between fuel assemblies in the storage racks is sufficient to maintain the array, when fully loaded and flooded with nonborated water, in a subcritical condition. A keff of less than about 0.95 for this condition is acceptable."

However, the conservatism required in the assumptions and analyses used to evaluate the effective multiplication constant, $k_{\text {eff }}$, of spent fuel basins has been reduced.

The reduction in conservatism required by the NRC in licensing analyses was made possible by the development of improved computer codes for neutronic analysis (which had taken place in preceding years), and by the expenditure of additional efforts by license applicants to demonstrate that the reduction of conservatism cannot result in non-conservative results (i.e., analyses always indicate that a system is more reactive than 
it actually is). Thus, the licensing process has demonstrated flexibility as long as changes can be demonstrated not to jeopardize system safety. One may therefore anticipate that licensing philosophy may evolve further, to allow the licensing of spent fuel disposal facilities justified by analyses which assume that the fissile content of spent fuel is less than that of fresh fuel. However, it seems clear that 1 imits will have to be set for the maximum residual fissile content (or minimum burnup) allowed for disposal, and that proven methods of conservatively predicting burnup effects will have to be developed.

In response to a question from the audience, the author of Ref. 6 provided additional insight into regulatory philosophy. When fixed neutron poisons are included in spent fuel storage rack design, and when the presence of these poisons is included in analyses demonstrating criticality safety, independent experimental verification of the presence of the poison material is required for licensing approval. The questioner inquired why in-situ neutron attenuation measurements were required even when quality assurance documentation was maintained demonstrating that identifiable materials had been traced through the fabrication process, had been physically installed in the racks, and were visibly present for verification. The answer was that, for a matter as important as criticality safety, double assurance of the presence of the neutron poison material was deemed necessary.

The conservatism indicated by the exchange described above has implications for the requirements which one may reasonably expect to be imposed for verification of fissile burnup when its effects are incorporated in demonstrations of the criticality safety of spent fuel disposal. It is a reasonable expectation that direct experimental verification of fissile burnup will be required to ensure that the fissile content of spent fuel accepted for disposal does not exceed some limiting maximum value. That value will then be the value assumed for demonstration of criticality safety of the disposal process. This conclusion is supported by an instance where spent fuel transport conducted under Atomic Energy Commission auspices utilized limits based upon calculations which included the effects of fissile burnup. Direct experimental verification of the subcriticality 
of the transport configuration which had been calculated to be subcritical was required. Pulsed neutron techniques were used to provide this verification. 8

It has been noted that there has never been a commercial spent fuel storage basin licensed under the assumption that the fissile content of spent fuel was reduced from that of fresh fuel. However, all licensed storage basins are at reactor sites except for those at closed reprocessing plants at Morris, IL (GE) and West Valley, NY (NFS). At a reactor site, provision must be made to store fuel elements removed from the reactor core regardless of burnup achieved. Therefore the design, operation and licensing of reactor storage basins to handle fuel in its most reactive form is only logical. It is likewise logical to relax this requirement for disposal operations which can exercise selective acceptance and/or packaging criteria. However, definition of the criteria remains to be done.

The continued accumulation of spent fuel in the absence of reprocessing has led to proposals to construct facilities to store spent fuel exceeding the capacities of reactor storage basins. This concept is referred to as away from reactor (AFR) storage. The NRC is presently developing regulations for such facilities, ${ }^{9}$ and one of the papers given at the Atlanta ANS meeting outlined NRC licensing considerations and experience to date with implementing this concept. ${ }^{10}$ Following presentation of this paper, one author (Gore) asked the NRC author of Reference 10 (Roberts) if he was aware of any considerations given to including the effects of fissile burnup in criticality safety demonstrations for AFR storage. He said that NRC had not addressed this concept.

There is another aspect of burnup which must be mentioned in this discussion of isotopic composition. That is the existence in spent fuel of fission products which act as neutron poisons and reduce its neutronic reactivity. On a geologic time frame, it is not certain that the fission products will remain with the fissile materials. Because they are different chemical species they may be subject to preferential leaching and transport 
from the disposal site if water intrusion occurs. This is in contrast to the reduction of uranium enrichment resulting from the fissioning of ${ }^{235} \mathrm{U}$. Plutonium in spent fuel is highly insoluble in the oxide form, as is uranium. If it were selectively removed from the fuel by leaching, the reactivity of the residue would not be enhanced (as would be the case if neutron poisons were removed). Consequently it is conservative to ignore the presence of fission products and assume the presence of plutonium when assessing the criticality potential of spent fuel.

The purpose of the above discussion is to indicate the total lack of precedent for reliance upon fissile burnup in the 1 icensing reviews of commercial installations handling or storing spent fuel. A significant amount of research, experimentation and demonstration will be required to set a new precedent for regulatory action by the NRC.

\section{Experimental Verification of Burnup}

From the preceding discussion it seems likely that the licensing of spent fuel disposal on the basis of analyses incorporating burnup effects will require experimental verification that the burnup has indeed occurred. Consequently, the status of nondestructive assay (NDA) systems to provide such verification is reviewed in this section.

Although a wide variety of NDA methods has been developed to assay fissile materials, spent fuel assay places certain special requirements on measurement systems. Spent fuel emits high radiation fields of both neutrons and gamma rays. Passive NDA systems, which analyze spontaneous emissions, must be able to function in the presence of both neutrons and gammas and to discriminate between them. Active NDA systems, which interrogate the spent fuel with radiation and measure its response, require high source intensity to override background radiation. Finally, since disassembly of spent fuel bundles is not planned, NDA system response must be sensitive to the effects of all rods in a spent fuel assembly, not just those closest to the detector. 
An extensive review of the literature on NDA methods for irradiated nuclear fuels was published in 1978. ${ }^{11}$ With regard to spent fuel from light water reactors Reference 11 concluded that, "The status of NDA techniques for LWR fuel assemblies is not yet satisfactory and must be studied further to develop reliable techniques." Note the use of the words "fuel assemblies" in this conclusion - measurement problems are compounded when assemblies containing hundreds of fuel pins are assayed, due to spatial nonuniformity of initial fuel loading and of burnup. Furthermore, rods on the outside of assemblies tend to absorb emissions from centrally located rods, particularly gamma rays.

Despite the needs for further study and actual system demonstration, the review goes on to anticipate that, "For reprocessing plants, it seems that systems using the approach of neutron interrogation with isotopic sources could determine the total fissile content of LWR assemblies. At present no method can accurately differentiate between the plutonium and uranium fissile contents of the assembly." This conclusion is based upon studies of two proposed assay systems, one of which would use either a ${ }^{252} \mathrm{Cf}$ or an antimony-beryllium neutron source, ${ }^{12}$ and the other of which would use rhodium-deuterium neutron sources. 13

The review of Reference 11 also notes that passive neutron techniques (involving detection of neutrons sponstaneously emitted from the spent fuel) appear promising and should be explored. A more recent document ${ }^{14}$ reports work on this technique. That document concluded that, "Our investigations indicate that the passive neutron assay is a simple and useful technique to determine the consistency of burnups between assemblies." A feature of this method is that neutrons originating in fuel pins located in the center of an assembly which are absorbed in outer fuel rods can cause fissions, and the resulting fission neutrons can then penetrate the assembly.

Finally, the nuclear reactivity of materials containing fissile materials can be (and has been) measured directly in critical and subcritical assemblies (reactor-like piles). This can be used as an assay 
method. Concerning this method the review of Reference 11 concludes, "This assay technique seems to be applicable to whole assemblies, especially the MTR-type [materials testing reactor] assembly that has a relatively small self-shielding effect. The main problem of the technique to assay an LWR spent assembly is to determine the plutonium and uranium fissile contents of the assembly separately. The cost of such an assay system is relatively high."

The recent emphasis on developing safeguards against diversion of fissile materials for illegal weapon use has motivated the studies of NDA techniques which have been described in this section. Consequently, the conclusions expressed above relate to the adequacy of the assay methods for achieving the objectives of safeguarding fissile material. Systems studies estimated that achievable accuracies were in the percent range, typically within $10 \%$. It is likely that the accuracy requirements for safeguarding fissile materials and ensuring criticality safety for spent fuel disposal in geologic media differ. Safeguarding fissile material requires accurate inventory measurements, whereas ensuring criticality safety requires only that fissile content be less than some limiting maximum. Furthermore, the importance of distinguishing between (low enriched) uranium and plutonium (potential weapon material) is much smaller for criticality safety than for safeguards purposes. Consequently, one may reasonably expect that determination that the fissile content of a spent fuel assembly is less than some limiting maximum will be no more technically difficult than meeting the assay accuracy requirements for safeguarding fissile materials. Therefore the quoted conclusions, which were based upon the accuracy requirements for safeguarding fissile materials, are expected to be also valid for ensuring criticality safety.

The almost total lack of quantitative detail in this discussion indicates a need for further study. The scope of this limited study was to determine if systems adequate for burnup verification existed, or appeared feasible with existing technology. The latter is the case. Consequently it is appropriate to incorporate the effects of verified fissile burnup in analyses of the criticality safety of spent fuel disposal. 
This will be done in future research efforts which will also assess the extent of burnup which must be assured for criticality safety in the disposal of entire fuel assemblies. The required burnup will in turn determine accuracy requirements for assay systems used to verify that burnup has taken place.

\section{Moderation}

When a neutron encounters a fissile atom, the probability that fission will result is dramatically dependent upon the speed, or energy, of the neutron. Slow, or "thermal" neutrons are the most effective. They result when fast fission neutrons collide with atoms of the material through which they are passing, and thereby lose energy through the collision process (moderation of the neutron energy). Hydrogen, the primary constituent of water, is the most effective moderator there is. (Because a hydrogen nucleus has essentially the same mass as a neutron, a neutron can transfer its entire energy to the hydrogen nucleus in a single elastic collision). Consequently, criticality control is often based upon limiting neutron moderation by excluding water. As a case in point, fresh $\mathrm{UO}_{2}$ fuel of $3.5 \%$ enrichment cannot be made critical in the absence of water or other moderation no matter how much of this pure dry material is accumulated. Water, however, is the most unbiquitous substance on the earth, covering more than half of its surface and regularly falling from the sky onto the land areas. Earth is often called the green planet, and its very greenness testifies to the presence of water in the soil, which is required for the survival of plants. Even in arid regions the soil is not completely dry.

Groundwater has proven to be a problem in the shallow land burial of low-level radioactive waste, leading to the unwanted transport of radionuclides from burial trenches. 15 The possible intrusion of groundwater into repositories for high-level radioactive wastes from spent fuel reprocessing is also of concern, since it could result in the leaching and transport of radionuclides in the biosphere. The salt mine site at Lyons, Kansas, which was proposed by the AEC to be the initial Federal repository for disposal of commercial high-level wastes, was eventually rejected and 
returned to its owners due to questions on possible routes of water entry into the mine. ${ }^{2}$

General geologic requirements have been developed for repositories for spent fuel or high-level radioactive wastes. These requirements clearly recognize potential problems associated with the presence of water. The following quotation is from Section 7.2 of Reference 2.

"The repository site should be located in a host rock unit of low permeability, porosity, and water content. The low permeability of the host rock formation would minimize movement of groundwater in and near the repository and create the maximum possible isolation from the groundwater flow systems which could transport and release radionuclides to the biosphere. The porosity and water content should be sufficiently low that the water within the host rock would not be affected chemically or thermally by the waste-generated heat on a large enough scale to compromise geological containment and operational safety."

"The repository should be located in a region where the groundwater hydraulic gradients are low. This would aid in reducing the rate at which groundwater would leave the repository site. In addition, the repository should be situated far away from any point where the site groundwater flow system discharges to the biosphere or is used by man."

"The repository medium and site should provide multibarriers that will enhance isolation of radioactive wastes. The multibarrier concept of isolation provides that the components of a repository site's geologic environment act together to provide isolation. Geologic multibarrier components are the depth, the disposal medium, media above and below the host rock, the hydrologic regime of the repository medium, the tectonic stability, and the low resource potential." 
The concepts of multiple barriers isolating the contents of a repository from the biosphere and the choice of favorable hydrologic settings for repository location indicate that repository design and siting will attempt to minimize the potential for water intrusion. This is important since moderation control is one of the more effective methods of criticality control, especially for systems containing low-enriched uranium. However, the ubiquity of water in the terrestrial environment plus the uncertain efficacy of water intrusion barriers over geologic times makes our ability to ensure moderation control questionable. Since the fissile nuclides remain undecayed longer than the integrity of any canister can be assured, and since the intrusion of water into spent fuel canisters cannot be precluded, water should be assumed to be present whenever it increases the neutronic reactivity of the system. This assumption was made without comment in discussions of the effects of mass and geometry which were presented earlier in this section. 


\section{EFFECTS OF MODERATOR EXCLUSION BY CLOSE-PACKED FUEL RODS}

Parallel to the review of NDA capabilities to verify fissil burnup, calculations were performed to assess a potential method for alleviating criticality concerns previously identified in studies which ignored burnup effects and assumed that the fissile content of the fuel was the same as that of fresh fuel. ${ }^{5}$ The concern, in a nutshel1, is that a 13 inch $(33.0 \mathrm{~cm})$ diameter cylinder of optimaliy moderated, $3.5 \%$ enriched $\mathrm{UO}_{2}$-water mixture having full water reflection would be critical. Such a situation could result from water intrusion coupled with disintegration of a $17 \times 17$ PWR fuel assembly (diagona] width 12 inches or $30.5 \mathrm{~cm}$ ) in a cylindrical canister having a reasonable clearance between the assembly corners and the canister.

The water-to-fuel (W/F) volume ratio in a fuel assembly is about 1.6. This corresponds to an average fuel density of $3400 \mathrm{~g} \mathrm{UO} / \mathrm{l}$. If however, the fuel rods disintegrate and the uranium oxide becomes uniformly distributed throughout the cylindrical canister the average fuel density decreases to about $2000 \mathrm{~g} \mathrm{UO}_{2} / l$. This range of concentration spans the most reactive, or optimally moderated, concentration of $2400 \mathrm{~g} \mathrm{UO}_{2} / \ell$. And, over this entire range of concentrations a 13 inch $(33.0 \mathrm{~cm})$ diameter cylinder of $3.5 \%$ enriched $\mathrm{UO}_{2}$-water mixture having full water reflection would be critical if the cladding separated from the $\mathrm{UO}_{2}$ during the disintegration process. At optimal moderation criticality would be of concern even if clad separation were incomplete.

Conceptual studies of packaging concepts for spent fuel disposal have identified the possibility of including a stabilizer material within each canister. Among the functions which this material could perform is the exclusion of water moderator. For this purpose stabilizer materials should be durable and insoluble. Spent fuel rods themselves might well be as effective in this role as other materials. Should this prove feasible within the requirements of neutronics and thermal-hydraulics a significant increase in the amount of fuel per disposal canister could result. 
Calculations were therefore performed to determine whether significant increases in allowed canister radius might be justified if water intrusion could be limited by fuel bundle disassembly and close-packing of the fuel rods.

It was recognized at the outset that this approach would have limited validity due to the uncertain ability to control the radius of a fuel-rod grouping over geologic time spans. However, possible situations in which it might be advantageous exist. For instance, canisters could be emplaced into carefully sized holes bored into solid rock formations. Or, they could be cast into special cement or polymer overpacks. Consequently, the analysis was undertaken to see if the idea held sufficient promise for further investigation.

The conclusion reached in the following discussion is that a limited increase in allowed canister diameter could be achieved with close-packing of the rods, but that it is much less than was initially anticipated. This is due to the inability to control the results of potential fuel rod disintegration within the canister. Nevertheless, for any canister size, close-packing significantly increases the number of fuel rods which can be accommodated.

The calculations performed to study the effects of moderator exclusion by close-packed fuel rods investigated the critical radius of a single canister loaded with PWR fuel pins typical of LWR fresh fuel. The fuel enrichment was assumed to be $3.5 \mathrm{wt} \%$. Other properties of the fuel are listed in Table II. Canister material was ignored since canister designs are not yet well defined. Water flooding was assumed, with full water reflection in most cases. Water is an excellent neutron reflector, and is representative for initial calculations. Some materials such as concrete, however, are more effective and the extent of this effect is indicated in a few calculations.

The calculations explored the variation of critical radius as a function of water/fuel volume ratio assuming a uniform hexagonal-pitch lattice 
TABLE II. PWR Fuel Rod Data

Fuel Element 0. D.

Clad Thickness

Fuel-Pellet Diameter

Fuel Enrichment

Pellet Density
$0.94 \mathrm{~cm}$

$0.0572 \mathrm{~cm}$

$0.819 \mathrm{~cm}$

$3.5 w t \%$

$95 \%$ theoretical 
in the fuel region. In the rods-touching limit this yields a hexagonal closepacked lattice and the variation with W/F volume ratio corresponds to different pin-to-pin spacings. Results are shown in Figure 2.

The calculations were performed using 20 group cross sections (19 fast groups, 1 therma 1) generated from the ENDF/B-IV library by the EGGNIT-II ${ }^{16}$ code. The critical radius of the fuel pin region was determined by an iterative search procedure using the 1-dimensional $\mathrm{HFN}^{17}$ diffusion theory code.

The accuracy of calculated results often suffers in calculations of relatively dry systems. Consequently limits of uncertainty for calculations of rod systems were estimated by calculating the effective multiplication factor, $k_{e f f}$, for a series of critical experiments performed at Argonne National Laboratory. 18,19 The experiments calculated covered a range of $W / F$ volume ratios from 0.4 to 1.4 . Fuel enrichment was $3.04 \%$, and other fuel parameters are listed in Table III. The results calculated for these experiments with the EGGNIT and HFN codes are shown in Figure 3 and compared with the experimental value of $k_{e f f}=1.00$. At the higher water-to-fuel ratios $k_{\text {eff }}$ values are $1 \%$ high which means that the calculations are conservative. At the lower water-to-fuel ratios the calculations are non-conservative. Extrapolation of the curve of Figure 3 indicates that for water-to-fuel volume ratios of 0.2 calculations may be non-conservative by as much as $4 \%$.

Figure 2 presents the critical radii calculated for water-reflected lattices of fresh fuel pins, along with radii calculated to yield $k_{\text {eff }}$ values of 1.012 and 0.976 (corresponding to the range found in the calculations for Figure 3). The water-to-fuel ratios of Figure 2 span packing possibilities ranging from standard LWR lattices to touching fuel pins in a close-pack hexagonal arrangement $(W / F=0.14)$. The calculations ignore any spacer grids and other hardware which might be associated with the fuel. Since hardware tends to depress the neutronic reactivity of the system this assumption is conservative. The results 


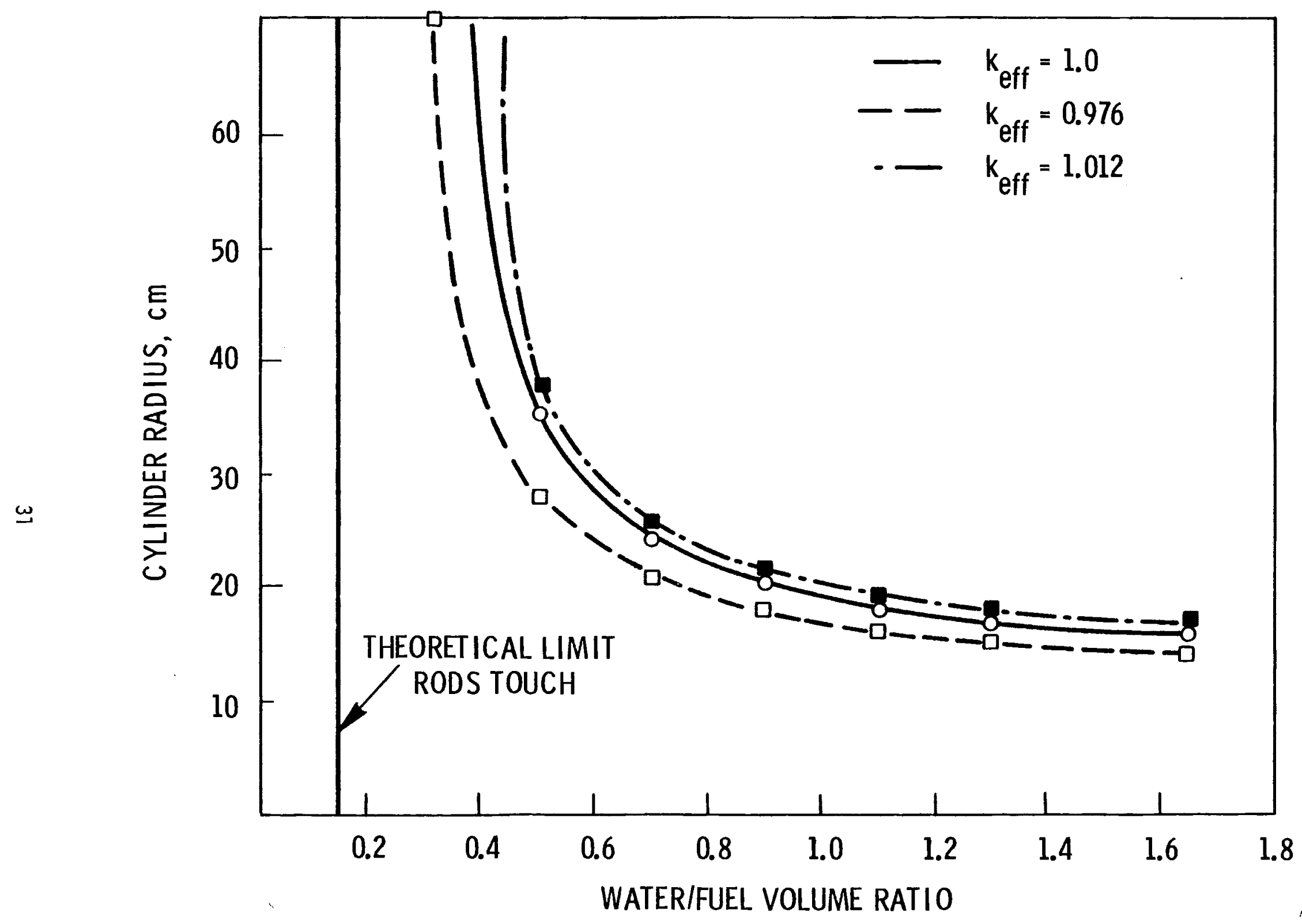

FIGURE 2. Calculated Radii of Critical Lattices 
TABLE III. Benchmark Experimental Fuel and $\mathrm{Cladding} \mathrm{Data}$

Fue1

$\begin{array}{ll}\text { Enrichment, w/o } & 3.0422 \\ \text { Radius, } \mathrm{cm} & 0.46736 \\ \text { Length, } \mathrm{cm} & 121.92 \\ \text { Oxide density, } \mathrm{g} / \mathrm{cm}^{3} & 10.2 \\ \mathrm{~N}^{25} \text {, a toms } / \mathrm{cm}^{3} & 0.0007013 \times 10^{24} \\ \mathrm{~N}^{28} \text {, atoms } / \mathrm{cm}^{3} & 0.02207 \times 10^{24} \\ \mathrm{~N}^{0}, \text { a toms } / \mathrm{cm}^{3} & 0.04554 \times 10^{24}\end{array}$

Cladding

Type

6061-T6 Al

Inner Radius, cm

0.48445

Outer Radius, $\mathrm{cm}$

0.52900

Density, $\mathrm{g} / \mathrm{cm}^{3}$

2.70

$\mathrm{N}^{\mathrm{Al}}$, atoms $/ \mathrm{cm}^{3}$

$0.0625 \times 10^{24}$ 


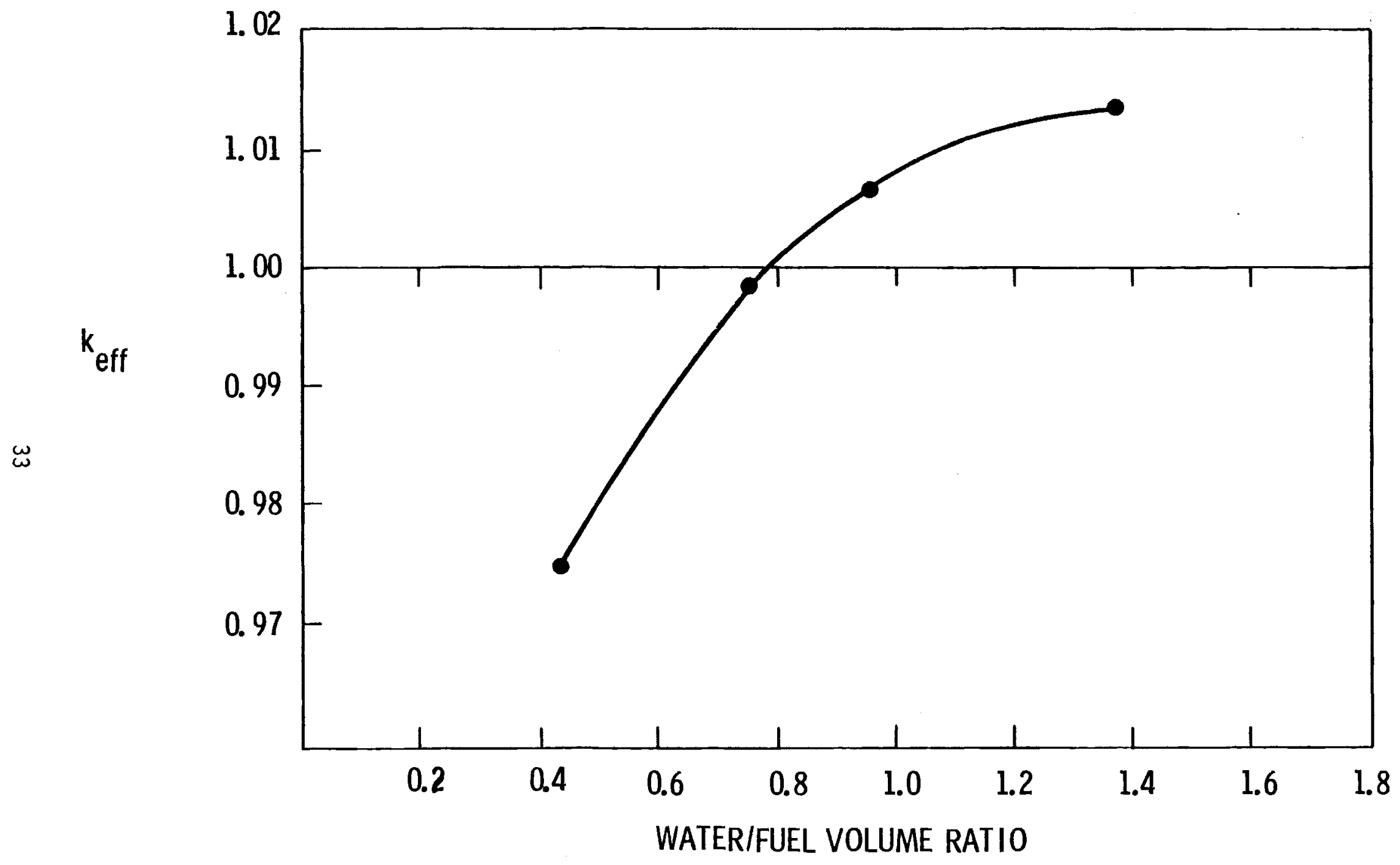

FIGURE 3. Calculated Values of Neutron Multiplication for Critical Experimental Lattices 
presented in Figure 2 show that displacing water by close-packing the fuel dramatically increases the critical radius, indicating the potential of this concept for criticality control.

The effects of neutron reflection by a reflector more effective than water are shown in Figure 4 . In this figure critical radii calculated assuming reflection by thick concrete are compared with those calculated assuming full water reflection. Comparison with Figure 2 shows that this effect is smaller than the error band associated with calculational uncertainty. Consequently neutron reflection by water only is assumed in the following.

The integrity of spent fuel rods is not assured over geologic time frames. Once the cladding is breached, fuel pellet disintegration may result. This could result from volume changes associated with further oxidation of $\mathrm{UO}_{2}$, which can occur at elevated temperatures. Therefore, additional calculations were performed to assess the effects of fuel pellet disintegration upon criticality. When it is assumed that the disintegrated fuel pellets and cladding mix uniformly and homogeneously, and that water fills all void space and surrounds the canister, the resulting mixture has a lower neutronic reactivity than the rods. Critical radius as a function of the original water/fuel volume ratio for the rods (cladding excluded) is plotted in Figure 5 and compared with the curve of Figure 2. The dramatic increase in critical radius resulting from close-packing the fuel rods is not jeopardized by fuel rod disintegration which results in uniform homogenization of the fuel and cladding.

However, separation of the fuel and cladding during the disintegration process cannot be preciuded. In Figure 6 the results of this process on critical radius are presented and compared with the curves of Figures 2 and 5. The data for this curve were interpolated from previously published calculations of $\mathrm{UO}_{2}$-water systems having $3 \%$ and $4 \%$ enrichment. ${ }^{4}$ 


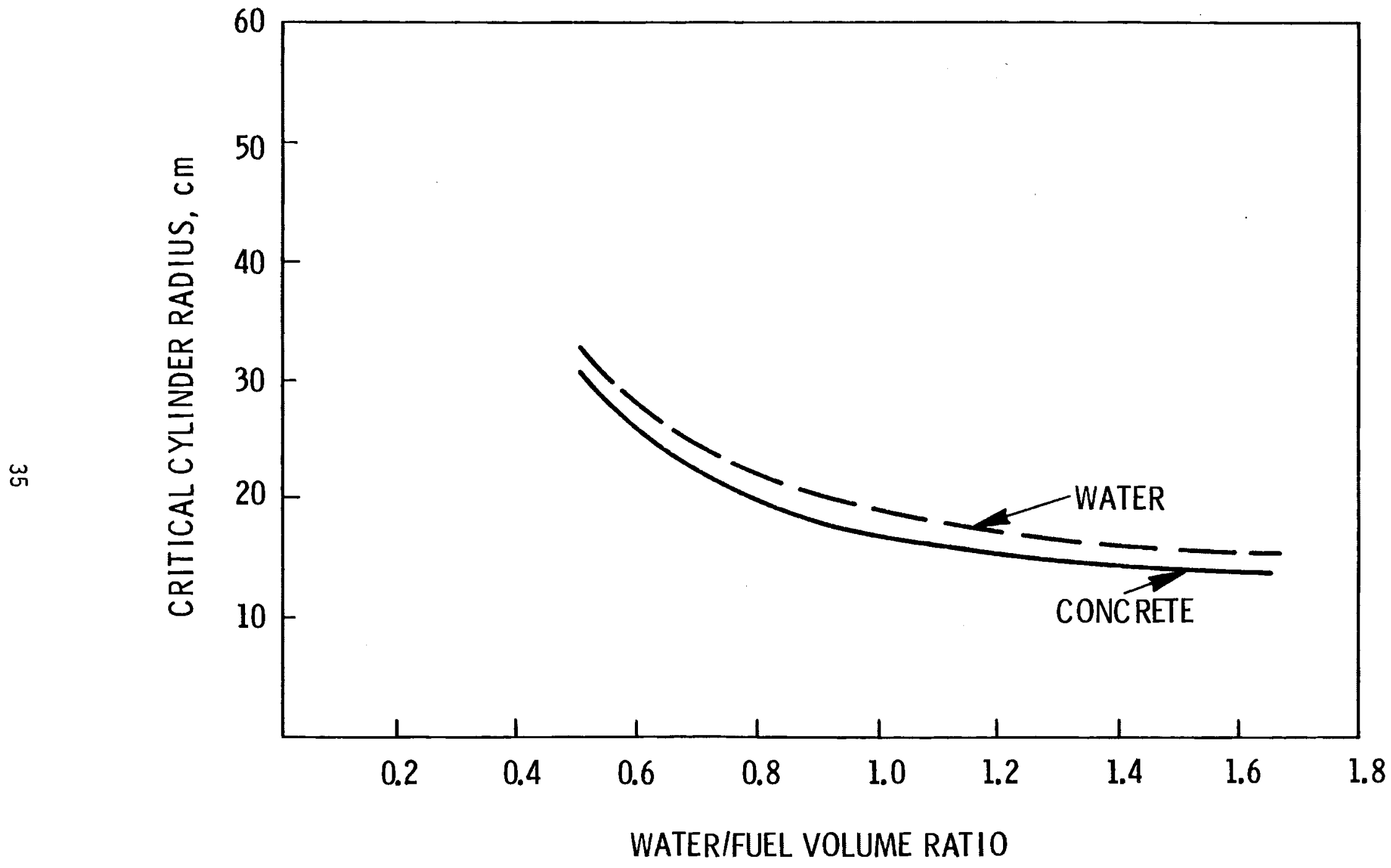

FIGURE 4. Critical Lattice Radii With Water and Concrete Reflectors 


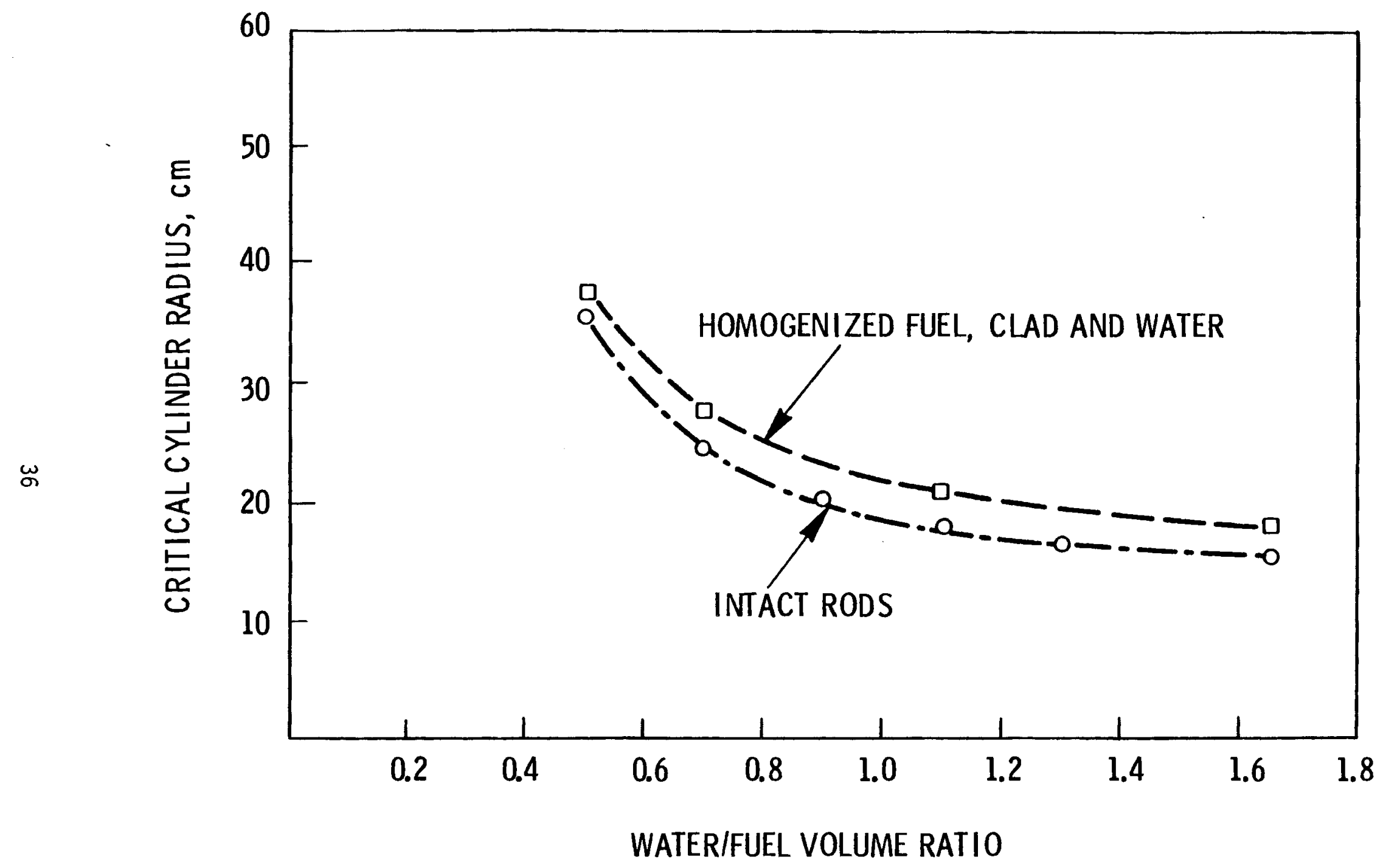

FIGURE 5. Effects of Uniform Fuel Rod Disintegration 


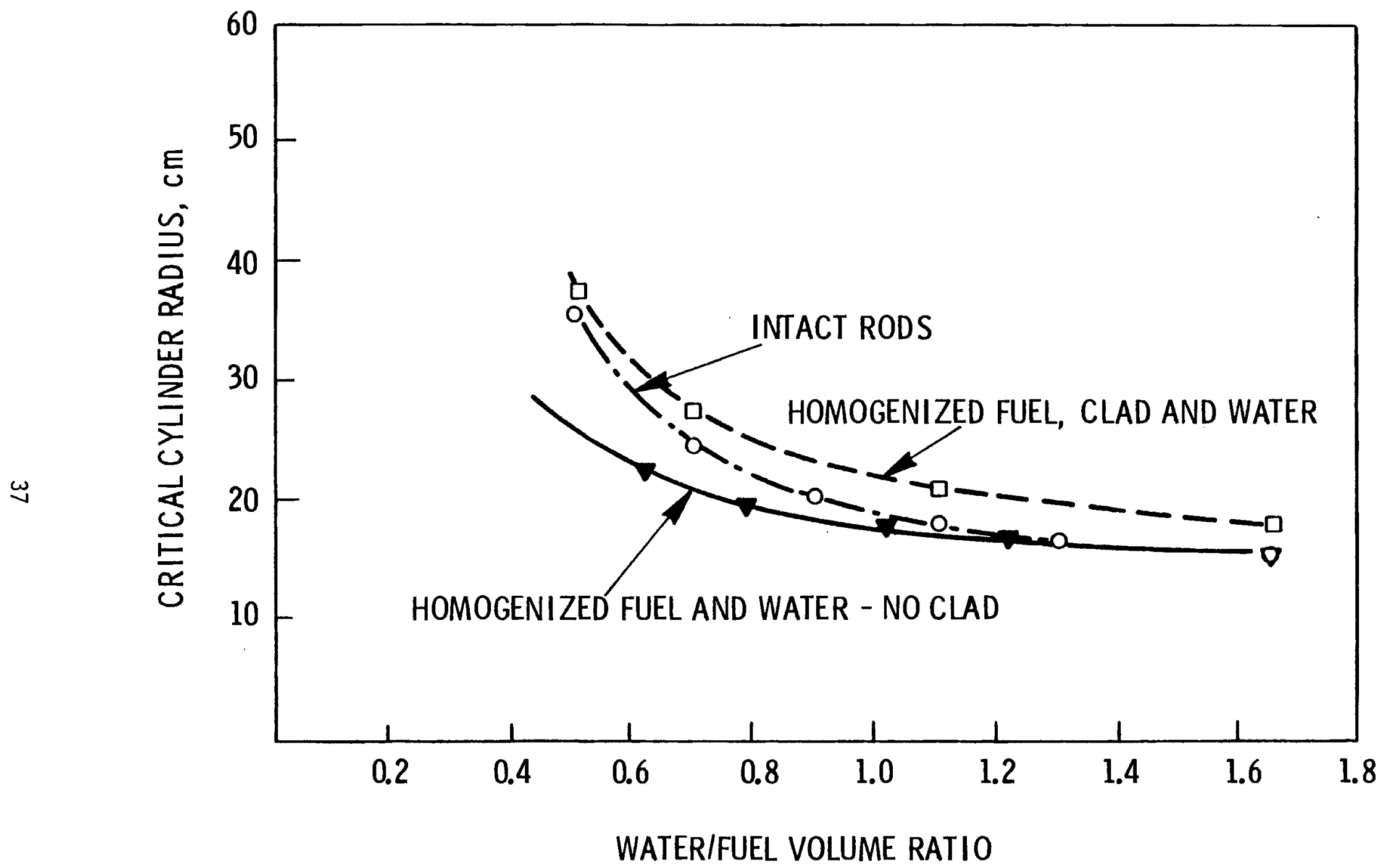

FIGURE 6. Effects of Cladding Separation During Fuel Disintegration 
In Figure 6 it is seen that the critical radius for $\mathrm{UO}_{2}$-water cylinders becomes less than that for cylindrical lattices of clad rods as moderation is decreased. It may seem surprising that homogeneous mixtures would be more reactive than rodded lattices of equivalent moderation. However, the reader is reminded that the fuel cladding, which is a significant fraction of the material in this system, has been assumed to separate from the $\mathrm{UO}_{2}$-water mixture. The volume of the cladding (ignoring end pieces, etc.) is $30 \%$ of the volume of the fuel pellets. At the theoretical limit of close-packing, when the rods touch, the clad occupies $20 \%$ of the total system volume. (At this limit the W/F volume ratio with cladding excluded is 0.14 ). Although the zironium cladding causes only a minor increase in parasitic neutron absorption, its presence reduces the density of the uranium in the system and significantly increases the radius required for criticality at low moderation.

Extrapolation of even the lowest curve of Figure 6 down to the rodstouching limit of $W / F=0.14$ indicates that considerable expansion of allowed canister radius would result if this limit could be achieved. Unfortunately, however, it cannot. Fuel rods in a reactor are subject to bowing due to thermal and irradiation effects. Bowing, along with deposits built up on fuel rod exteriors, will prevent achievement of the W/F limit for close-packed rods. This effect is larger than one might expect a-priori.

Examination of spent fuel pins ${ }^{20}$ yields an average bowing measurement of $0.02 \mathrm{in.}$ (about the same as the cladding thickness) with a maximum of 0.05 inches. Assuming that the hexagonal close-packed lattice pitch is increased by these amounts respectively yields limiting water/fuel volume ratios of 0.3 and 0.56 , respectively. In practice the limiting $W / F$ ratio achievable would lie between these two values, within the cross-hatched region shown in Figure 7 . It is perhaps worth noting here that attempts to compress such close-packed lattices closer to the theoretical limit could prove counterproductive if the (brittle) fuel rod cladding failed, releasing fission products. Consequently, reduction of the limiting $W / F$ value to or below 0.3 may not be possible. 


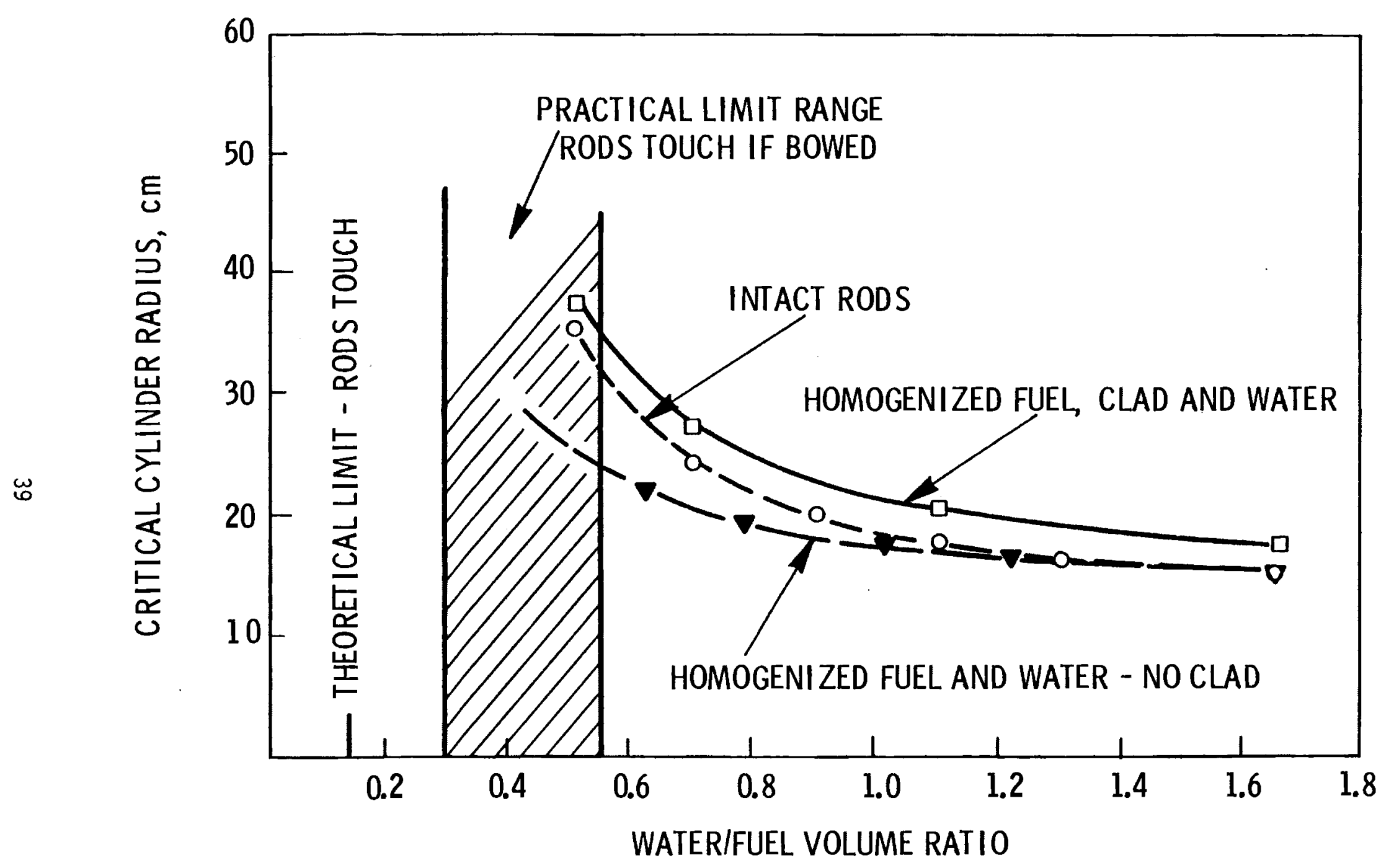

FIGURE 7. Effects of Limits to Close-Packing Caused by Fuel Rod Bowing 
Finally, there is yet another limitation on the minimum practical W/F ratio achievable within a canister containing close-packed spent fuel rods. Some sort of hardware (strapping perhaps) must be used to bundle the close-packed rods together, and clearance must be provided for inserting the bundled rods into the disposal canisters. Upon eventual fuel rod disintegration this extra space is available to further reduce the achievable $W / F$ ratio. As a specific example, if the rods are bundled tightly so that $W / F=0.4$ in a bundle of $25 \mathrm{~cm}$ radius, and if a $1 / 2$ inch radial clearance is allowed for inserting the bundle into the canister, upon uniform disintegration $W / F=0.58$ would result . Additional increase would result when the effects of end pieces included in fuel rods and assembly hardware, and in the canister end cap design, are included.

As a result of the effects of rod bowing and required canister clearance, coupled with the potential effects of fuel rod disintegration, it is concluded that the potential for a dramatic increase in allowed canister size which is indicated by the results presented in Figure 2 cannot be achieved by close-packing spent fuel rods in disposal canisters. As can be seen in Figure 7, limited size increases may be justifiable. However, they would require more careful quantification of rod bowing effects and more detailed information on canister design, side clearance, and end effects. It is not clear that such efforts are justified to achieve the limited gains indicated achievable in Figure 7.

In view of the above discussion it is concluded that, for the sake of conservatism and straightforward analys is practices, spent fuel disposal canisters should be sized on the basis of optimum moderation of their contents (either rods or homogeneous oxide-water mixtures, whichever is more restrictive). Within this restriction close-packing offers advantages in that more fuel rods can be inserted in a given canister, reducing the number of canisters required. The repository space required for disposal might also be reduced, but not if canister spacing is determined by thermal loading limitations. Disadvantages of close-packing include the increased handling required for fuel bundle disassembly and canister packing. These 
disadvantages, coupled with the potential for cladding failure during handling operations required for close-packing, may result in the disposal of intact assemblies being preferred.

As was indicated at the beginning of this section, a canister capable of receiving a $17 \times 17$ rod PWR fuel bundle has a diameter greater than the critical diameter for a homogeneous, optimal1y-moderated, $3.5 \%$ enriched $\mathrm{UO}_{2}$-water system reflected by water. Consequently, demonstrations of criticality safety in the geologic disposal of complete spent fuel assemblies will almost certainly require incorporation of fissile burnup in the analysis. This means that limits must be established for the fissile content allowed in spent fuel which is accepted for geologic disposal as intact assemblies, and that measurement systems to verify adherence to these limits must be constructed and demonstrated. Otherwise, it may be necessary to restrict canister dimensions and contents so that an entire assembly of low burnup or unverified burnup fuel cannot be placed in a single canister. 


\section{RESEARCH TOPICS FOR FURTHER STUDY}

The discussions presented in this document have addressed the difficulty of demonstrating criticality safety of spent fuel disposal over geologic times. Serious problems have been identified for disposal of complete assemblies of PWR fuel when fissile burnup is ignored or has not occurred. The lack of demonstrated systems to verify the occurrence and extent of fissile burnup in spent fuel assemblies has been reviewed.

Clearly, then, the prime topic for further study is the determination of acceptance criteria concerning the residual fissile content in spent fuel assemblies destined for geologic disposal. A possible acceptance criterion for disposal of intact spent fuel assemblies could be the inability of the mixed actinide contents of an assembly to cause criticality regardless of form, geometry, moderation, or reflection. Such a criterion could also be used for low burnup fuel to limit the fraction of a fuel assembly allowed per disposal canister. However, it is not now known whether such a criterion would yield workable limits or whether it might prove to be overly restrictive.

It is likely that the maximum fissile content acceptable in fuel assemblies to be disposed of as intact units will correspond to a lower burnup value than is routinely expected for power reactor fuel. Calculations $^{21}$ indicate that a one meter radius sphere of the actinide oxide contents of spent fuel burned to an exposure of 33,000 MWD/MTU would not be critical. This supports the expectation that acceptable burnup values will not be excessive. Other calculations, however, which consider only the isotopes, ${ }^{235} \mathrm{U},{ }^{238} \mathrm{U}$ and the plutonium isotopes indicate a higher neutronic reactivity. ${ }^{22}$ The neutron absorption effects of other uranium isotopes, of the actinide isotopes of neptunium, americium, and the fissile effects of the isotopes of curium are ignored in the latter study, so the result does not necessarily indicate a contradiction. Determination of just 
which isotopes must be considered is part of the needed study. This study is planned for performance at PNL during FY-1980.

It is not considered likely that hydrologic transport mechanisms will result in separation of plutonium from the other actinides in spent fuel. 23 However, should Pu separation occur a scenario exists which could lead to trouble. Dilute concentrations of $\mathrm{Pu}$ dispersed throughout large volumes of soil will remain subcritical while the soil is wet, but can become critical upon partial drying from a saturated condition. If sufficient $\mathrm{Pu}$ were accumulated before drying commenced, it is possible that moisture evolution might be insufficient to terminate the chain reaction. Should this be the case, physical dispersal would be required for shutdown. The minimum quantity of $\mathrm{Pu}$ required for this contingency needs to be determined. The effects of Pu isotopic content and soil composition should be included. The effects of poisons, including other actinide isotopes which may travel with $\mathrm{Pu}$ also need to be evaluated to help determine if such a scenario is credible under the conditions of spent fuel disposal. In particular, the minimum admixture of low enriched uranium which may make this scenario impossible needs to be determined. This study is also planned for performance at PNL during FY-1980.

Consideration needs to be given to scenarios which could result in criticality within a repository setting (including possible effects of multiple canister aggregations). During FY-1980 collaboration will be undertaken with members of PNL's program for the Assessment of Effectiveness of Geologic Isolation Systems (AEGIS Program) to determine which scenarios are credible and which are not. Although we cannot control repository conditions over geologic times, if it can be shown that combinations and sequences of geologic events required for criticality to occur are sufficiently unlikely to be considered not credible, then such scenarios can be dismissed from consideration.

If credible scenarios leading to criticality in a repository setting are identified, the magnitude, duration and consequences of the excursion 
should be evaluated. It is to be expected that events which make criticality possible may fundamentally alter repository conditions, including natural and man-made barriers between repository contents and biosphere. The scenarios resulting in criticality should be examined to identify expected repository conditions which might limit the magnitude of the critical excursion. Limiting water supply rates, heat transfer rates, possible steam venting effects and other phenomena should be examined to determine their effects. The objective of these studies would be to determine production rates of radionuclides and allow comparison of resulting reaction products with radionuclides present in the spent fuel. Among factors to be considered here would be the time between emplacement of fuel in the repository and occurrence of the criticality. The results of fission product decay, which reduces fission product inventories by a factor of a million within a thousand years of emplacement, should be incorporated. Finally, credible rates and duration of radionuclide releases should be determined. The significance of such releases should then be determined by comparing them with releases estimated for contingencies which might result from events not related to nuclear criticality (breach of natural barriers and waste canisters caused by earthquake faulting, for instance). 


\section{REFERENCES}

1. Environmental Aspects of Commercial Radioactive Waste Management, DOE/ET-0029, U.S. DOE, Washington, DC, May 1979.

2. Technology for Commercial Radioactive Waste Management, DOE/ET-0028, U.S. DOE, Washington, DC, May 1979.

3. R. E. Westerman, Preliminary Conceptual Designs for Advanced Packages for Geologic Disposal of Spent Fuel, PNL-2990, Pacific Northwest Laboratory, Richland, WA, April 1979.

4. R. D. Carter, G. R. Kiel and K. R. Ridgeway, Criticality Handbook, ARH-600, Atlantic Richfield Hanford Company, Richland, WA, June 1968.

5. S. W. Heaberlin and G. P. Selby, Criticality Safety Comparisons of Spent Fuel Facility Concepts, PNL-2590, Pacific Northwest Laboratory, Richland, WA, September 1978.

6. T. J. Carter, "Status of Spent-Fuel Storage Pool Applications," Trans. Am. Nuc1. Soc., 32, 677 (1979).

7. Standard Review Plan: Section 9.1.2 Spent Fuel Storage, U.S. NRC Office of Nuclear Reactor Regulation, Washington, DC.

8. R. W. Miller and H. Toffer, Criticality Control Parameters for Discharged Fuel, DUN-SA-193, Douglas United Nuclear, Inc., Richland, WA, October 1972 .

9. R. E. Stanford, "Status of Pertinent Regulations and Regulatory Guides for Independent Spent-Fuel Storage Installations," Trans. Am. Nucl. Soc., 32, 680 (1979).

10. J. P. Roberts, "Licensing Considerations and Experience with Applications for Independent Spent-Fuel Storage Installations," Trans. Am. Nucl. Soc., 32, 680 (1979).

11. S. T. Hsue, T. W. Crane, W. L. Talbert, Jr. and J. C. Lee, Nondestructive Assay Methods for Irradiated Nuclear Fuels, LA-6923, Los A1amos Scientific Laboratory, Los Alamos, NM, January 1978.

12. T. Gozani, Active Direct Measurement of Residual Fissile Content in Spent Fuel Assemblies, Electric Power Research Institute Report EPRI1278-1 (July 1975), also T. Gozani, "Non-destructive Assay of Spent Fuel for Determination of Residual Fissile Content," Proc. 17 th Annual Meeting of the Institute of Nucl. Mater. Mange., Seattle, WA, June 22-24, 1976, pp. 514-524. 
13. G. L. Ragan, R. S. Booth, T. J. Burns, J. D. Jenkins, C. R. Weisbin and L. R. Williams, "System for Assay of Fissile Content of Spent LMFBR Fuel Subassemblies," Trans. Am. Nucl. Soc., 23, 95-96 (1976).

14. S. T. Huse, J. E. Stewart, K. Kaieda, J. K. Halbig, J. R. Phillips, D. M. Lee and C. R. Hatcher, Passive Neutron Assay of Irradiated Nuclear Fuels, LA-7645-MS, Los Alamos Scientific Laboratory, LoS ATamos, NM, February 1979.

15. D. A. Webster, "Land Burial of Solid Radioactive Waste at Oak Ridge National Laboratory, Tennessee: A Case History," Management of LowLevel Radioactive Waste, Vol. 2, edited by M. W. Carter, A. A. Moghissi and B. Kahn, Pergamon Press, 1979.

16. C. R. Richey, EGGNIT: A Multigroup Cross-Section Code, BNWL-1203, Battelle-Northwest, Richland, WA, November 1969.

17. J. R. Lilley, Computer Code HFN - Multigroup, Multiregion Neutron Diffusion Theory in One Space Dimension, HW-71545, General Electric Co. 1961 .

18. A. R. Boynton, Q. L. Baird, K. E. Plumlee, W. C. Redman, W. R. Robinson, G. S. Stanford, High Conversion Critical Experiments, ANL-7203, Argonne National Laboratory, Argonne, IL, January 1967.

19. E. M. Pennington, Analysis of High Conversion Critical Experiments, ANL-7270, Argonne National Laboratory, Argonne, IL, March 1967.

20. D. H. Locke, et. al., "Water Reactor Fuel Performance," Nuclear Energy, $17 / 3,185-204$, July 1978.

21. E. J. Allen, Criticality Analysis of Aggregations of Actinides from Commercial Nuclear Waste in Geologic Storage, ORNL/TM-6458, Oak Ridge National Laboratory, Oak Ridge, TN, August 1978. The calculational survey reported in this document was terminated when criticality was not obtained for a one-meter sphere of the mixed actinides at theoretical density. However, the author has informed us that unreported calculations performed since publication of the document yielded the same results for water moderated spheres.

22. S. W. Heaberlin and G. P. Selby, Effect of Fissile Isotope Burnup on Criticality Safety for Stored Disintegrated Fuel Rods, PNL-2589, Pacific Northwest Laboratory, Richland, WA, September 1978.

23. D. G. Brookins, Geochemical Constraints on Accumulation of Actinide Critical Masses from Stored Nuclear Waste in Natural Rock Repositories, 0NWI-17, Battelle/Office of Nuclear Waste Isolation, Columbus, OH, December 1978. 


\section{DISTRIBUTION}

No. of

Copies

UNITED STATES

A. A. Churm

DOE Chicago Patent Group

9800 South Cass Avenue

Argonne, IL 60439

27 DOE Technical Information Center

Battelle Memorial Institute

Office of Nuclear Waste Isolation

Attn: Beverly Rawles

505 King Avenue

Columbus, $\mathrm{OH} 43201$

50 A. A. Bauer

Office of Nuclear Waste Isolation

Battelle Memorial Institute

505 King Avenue

Columbus, $\mathrm{OH} 43201$

Shirley Bell

Allied General Nuclear Services

P.0. Box 847

Barnwel1, SC 29812

Carl R. Cooley

DOE Office of Nuclear Waste Management

Washington, DC 20545

Colin A. Heath

DOE Division of Nuclear Waste Management

Washington, DC 20545

Ronald J. Hall

Office of Nuclear Waste Isolation

Battelle Memorial Institute

505 King Avenue

Columbus, $\mathrm{OH} 43201$
No. of

Copies

J. B. Martin

Asst. Director for Radioactive Waste Management Branch

NRC Division of Materials and Fuel Cycle Facility Licensing Washington, DC 20555

J. 0. Neff

Department of Energy

Columbus Program Office

505 King Avenue

Columbus, $\mathrm{OH} 43201$

ONSITE

4 Rockwell Hanford Operations

M. S. Bensky

R. N. Gurley

D. A. Turner

R. A. Deju

3 DOE Richland Operations Office

P. A. Craig

H. E. Ransom

J. J. Schreiber

30 Pacific Northwest Laboratory
A. Brandstetter
S. R. Bierman
C. L. Brown
E. D. Clayton
B. M. Durst
B. F. Gore (5)
S. W. Heaberlin (5)
R. C. Loyd
G. W. McNair (5)
A. M. Platt
R. D. Widrig
Publishing Coordination (2)
Technical Information (5) 
